\title{
Energy - Saving Potential of Evaporative Cooling System for Building Application - A Review
}

\author{
${ }^{1}$ Dr. Harish S. Bhatkulkar, ${ }^{2}$ Mr. Rohit M. Dhakare, ${ }^{3}$ Mr. Pravin Singh \\ ${ }^{1}$ Associate Professor, ${ }^{2,3}$ Student, S.B. Jain institute of Technology Management and Research, \\ Nagpur, India. \\ 1'harishbhatkulkar@sbjit.edu.in, ${ }^{2}$ rohitdhakre.me@sbjit.edu.in, ${ }^{3}$ psingh2865@gmail.com
}

\begin{abstract}
The function of air conditioning systems has seen impressive development over the most recent couple of decades everywhere throughout the world, particularly in commercial buildings in ensuring the occupant thermal comfort. All the same, it is followed to have bad effects on the earth as well as increased power consumption in buildings. Hence, there has been extensive research to recognize options, in contrast to conventional vapour compression air conditioning systems. This account intends to review the ongoing improvements concerning evaporative cooling advancements that might give adequate cooling comfort, reduce environmental impact and lower energy consumption in buildings. Researches have done as on date in evaporative cooling systems centre predominantly around mainly on drawing down the dry bulb temperature of the incoming air. The theoretical efficiency of $100 \%$ can be achieved when the room dry bulb temperature is equal to the wet-bulb temperature of the outside atmospheric air. A wide literature review has been carried out and mapped out the best evaporative cooling systems. The review covers direct evaporative cooling, indirect evaporative cooling, and combined direct-indirect cooling systems.
\end{abstract}

Keywords: Dry bulb temperature, Efficiency, Evaporative cooling advancement, Power consumption, Thermal comfort, Wet bulb temperature.

\section{INTRODUCTION}

It is reported that from the total primary energy use globally, nearly 30 to $40 \%$ energy is utilized for building for maintain comfortable indoor conditions for occupants. Owing to the kind of simplicity and flexibility, window or split type air conditioners are more common in residential and commercial buildings. These type of air condenser normally use air condenser for rejecting latent heat to condensing medium in the cycle. The functioning of these air condenser found reasonable as long as the ambient temperature is moderate and not too high. But in the region of high temperature like summer in vidarbha areas, the performance of these air condenser in air conditioners drops with corresponding rise in the power consumption because under high ambient temperature , compressor has to work under the greater pressure ratio [1]. Sometimes situation become so worst that the air conditioner may get trip down at very high ambient temperature. So to get rid of all these issues in the region of high temperature, it is very necessary to cool down the hot ambient air before it entered over the condenser coil to decrease thetemperature and pressure of the condenser. The most feasible and simple method of cooling the ambient air is the use of the evaporative cooling system. Use of such methodology may result in significant improvement in the saving of energy since there are millions of air conditioners in the residential sector and any small reduction in power consumption of an air conditioner could save a huge amount of megawatt in the network. Presently mechanised vapour compression coolers (MVC) are commercially dominant despite their intensive energy use and low performance in the hot climate. In contrast, evaporative cooling systems are more environmentally friendly as they consume less energy and their performance improves as air temperature increases and humidity decreases. However, the main drawback of the evaporative cooling is their high dependency on the ambient air conditions. Since the temperature difference between the dry- and wet-bulb temperatures of the ambient air is the driving force of evaporative cooling. For mild and/or humid climate this difference is small, therefore, leads to limited cooling capacity [2].

\section{LITREATURE REVIEW}

Nowadays, the air conditioning device is dominated through mechanical vapour compression systems, which are power intensive and suffer from poor thermal performance in hot weather regions. There is an effective utility of the evaporative cooling which can give a viable 
solution for cooling in hot and dry regions. This cooling method makes the use of the principle of water evaporative for absorbing the heat in the environment, so it uses very little electricity compared to the mechanical compression system. Currently, two types of evaporative cooling systems direct and indirect evaporative cooling systems are most common in use. [3]The direct evaporative cooling system makes use of the latent heat of evaporation to decrease the temperature of the air, which changes the warm air to cool and moist air. Indirect evaporative cooling systems have the advantage of decreasing the air temperature without increasing the humidity of the conditioned space. The present paper reviews various studies carried out related to the evaporative air cooling recently and the past. The cooling efficiency of the evaporative cooling system is found to be increased by imparting the following three methodologies in the system, viz., (i) Introduction of suitable components for effective evaporation; (ii) Combining direct and indirect cooling systems; and (iii) Utilization of different pad materials with different thicknesses.

\section{A. Evaporation rate enhancement studies:}

Giabaklou and Ballinger [4] had attempted to study the effectiveness of a passive evaporative cooling system and providing natural ventilation i.e. (through atmospheric air). The front faces of a building are provided with water guide filaments and where water flows from the top to bottom by the gravitational force. The incoming air then gets cooled as well as humidified and then enters the building. Such a system is found to reduce the temperature of incoming air (through evaporative cooling) by $9.9^{\circ} \mathrm{C}$, averaged over a day. Giabaklou et al [5] had extended the study by using PMV (Predicted Mean Vote) methodology; using such a system can improve PMV significantly when the number of air changes per hour is higher.

Nishikant Z. Adkane, Saroj V. Borkar, Ramesh D. Bokde [6] had worked on a Domestic refrigerator and then done a detailed comparative analysis between the water-cooled condenser and air-cooled condenser. In this paper after the experimentation is done on an evaporative cooling system at $40 \mathrm{~W}$. Then is to be graph is being plotted with the relation of COP (Coefficient Of Performance), R.E.(Refrigeration Effect)) with respect to time and then we come to a final conclusion that the refrigerator works simply and efficiently with the water-cooled condenser. By the usage of the water-cooled condenser, the COP can be increased up to $86 \%$ [6].

Kittas et al [7] had investigated the temperature and humidity gradients in (summer season) on greenhouse which are equipped with a ventilated cooling-pads system and it is also provided with half shade plastic roof. The cooling performance is observed to be increased up to 80 $\%$ is reported. The temperature of the greenhouse is observed to be lowered by $10^{\circ} \mathrm{C}$ compared to the outside air.
He and Hoyano [8] had studied then investigated on the cooling effect on the passive evaporative cooling wall which is constructed of porous ceramic materials. It has been reviewed after the investigation that the cooling efficiency was reached to a maximum of 0.7 during sunny daytime periods (in summer days) and it was observed that higher cooling efficiency was obtained under windy conditions (in winter days) where wind speed varies from 1-3 $\mathrm{m} / \mathrm{s}$ in continuously blowing during the testing. Then they had also reviewed a hybrid system of nocturnal radiative cooling and direct evaporative cooling and it was observed that up to $13.5{ }^{\circ} \mathrm{C}$ reduction in indoor temperature was reported.

Taufiq et al [9] had conducted an experimental investigation on the energy analysis of the evaporative cooling system by reducing energy expenditure in a building. Therefore, the relationship must be developed between relative humidity, energy efficiency, and also between ambient temperature and energy efficiency. It was reviewed form this experimental investigation that when the relative humidity of the system is increased, the use of energy also observed to be increased. It is also reviewed that evaporative cooling can be considered as a feasible technology that can be used effectively to reduce mechanical cooling and energy requirement.

\section{B. Studies on Indirect / Direct evaporative cooling system:}

Datta et al (1987) had experimentally studied on 8.5 ton indirect-direct evaporative cooling system and had reviewed that by the use of such a system we can provide a relief cooling rather than comfort cooling. The room temperature could be maintained at $4-5^{\circ} \mathrm{C}$ and above the inlet wet bulb temperature (WBT) by using such a cooler. The use of Indirect-direct evaporative cooling for residential use in arid regions like Israel was attempted by Navon and Arkin[10]. Such a system can be used more effectively to provide a higher level of thermal comfort where external humidity is around $80 \%$.

Gomez et al [11] had investigated and developed a ceramic evaporative cooling system that can be used as a semiindirect cooler. The cooled water which is supplied from the cooling tower is then passed through the annulus passage through the ceramic tube. The outside air (atmospheric air) is then passed through the central region. Chilled water (cooled water) then evaporates by seeping through the pores. Using such a system allows the recirculation of indoor air, which is not possible in the conventional evaporative cooling system. The use of such a system is experimentally observed and then reviewed that $5-12{ }^{\circ} \mathrm{C}$ temperature is dropped which is obtained under various conditions. 


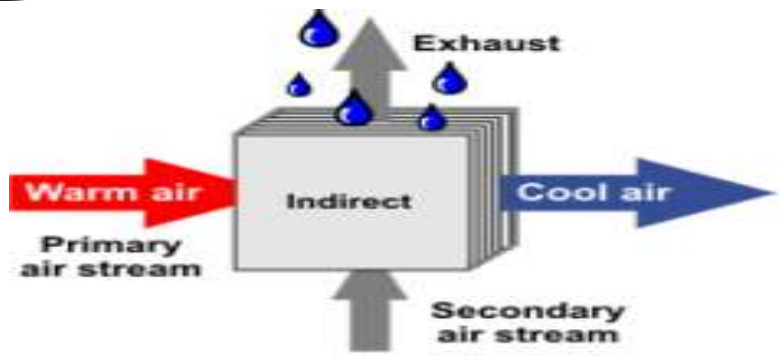

Figure 1: In-direct evaporative cooling system

Dai and Sumathy [12] had investigated a cross-flow direct evaporative cooler, in which they had used a wet durable honeycomb paper that can be used as a packing material. A mathematical model is then to be developed which includes the governing equations of liquid film and gas phases as well as the interface conditions of the system provided. The interface temperature of the falling film has to be predicted and the variation of temperature, humidity ratio in the flowing channel, the effect of system size and effect of operating parameters as inlet temperature, the humidity of inlet air and temperature of feed water are studied and observed for the recording of data. The liquidgases interface temperature is then to be predicted and the evaporative cooling process of falling film is then analyzed quantitatively. The optimum length of the air channel also has to be recorded.

Workneh et al [13] had investigated the effectiveness of forced ventilation evaporative cooling systems during the storage of tomatoes and the storability of pre-harvest treated tomatoes using evaporative cooling methods. Average dry bulb temperature (DBT) of ambient air and inside the evaporative cooling had been observed and recorded at $32{ }^{\circ} \mathrm{C}$ and $20.5{ }^{\circ} \mathrm{C}$ respectively. An average temperature drop which was observed and found to be $11.5^{\circ} \mathrm{C}$. The average relative humidity of ambient air and inside the evaporative cooling is then recorded as $40 \%$ and $83.9 \%$ respectively. Then it was found that the average difference between the inside and outside relative humidity during the test is $43.9 \%$.

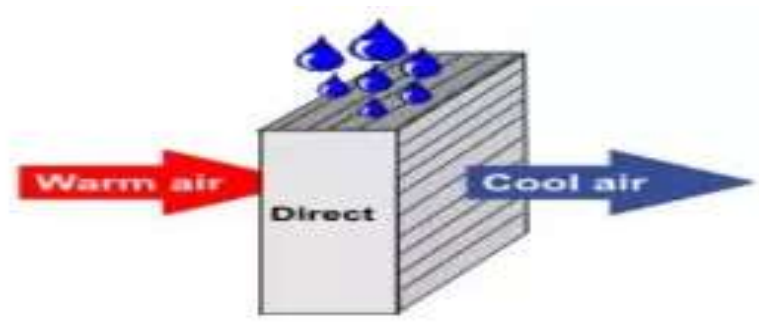

Figure 2: Direct evaporative cooling system

Chaktranonda and Doungsong [14] had experimented and evaluated on the energy savings technique in a split-type air conditioning with an evaporative cooling system. It was observed that the ambient temperature of the air has been influenced by power consumption by compressor and COP. When the air temperature is raised by $1{ }^{\circ} \mathrm{C}$, then it is observed that electrical power consumption is increased by around $4 \%$. It occurs due to high contact surface between water and air-stream; the evaporative cooling system can effectively decrease the power consumption by around 15 $\%$. Therefore, it can increase COP by up to $45 \%$.

\section{Studies related to a two-stage evaporative cooler:}

El-Dessouky et al [15] had carried-out the experimental investigation on performance on analysis of two-stage evaporative coolers. The system is to be operated as a function of the packaging thickness and the water flow rate of the DEC unit. The efficiency of IEC and DEC units, when operated individually, was found to be $20-40 \%$ and $63-93 \%$ respectively, whereas the efficiency of two-stage IEC/DEC varied over a range of $90-120 \%$.

D. Studies on the modelling of evaporative cooling systems:

A mathematical model is the representation of a device or concept which uses a number of variables and represents inputs and sets of equations or inequalities to describe their interaction. Mathematical models developed for the evaporative cooling system are mainly used to predict the system behaviours like cooling efficiency, temperature drop, and optimum air velocity for various inlet conditions.

Kimmel et al [16] had developed a theoretical model of an evaporative cooling in which a wetted hide and simulations have shown that the evaporative effectiveness and effective wetness depends on the parameters like temperature, humidity, and air velocity and on intrinsic local properties such as water content and distribution within the hide.

Sweetland and Lienhard [18] had developed a mathematical model using a Karman-Pohlhausen treatment of the velocity and thermal boundary layers accounting onthe evaporation of an entrained water spray and also investigated the effect of water sprays commonly used to cool freshly drawn glass fibres. In general, a reasonably good matching between the model and experimental data are reported in these studies.

\section{CONCLUSION}

Following are the conclusion that can be drawn from the reported literature review.

Due to increase demand of occupants for thermal comfort, building energy consumption is increases at very high rate. The high energy demand, high energy cost and the global warming demanding some improved energy systems to enhance energy efficiency and at the same time curtailing greenhouse gas emissions [26]. This is a reason of giving more concern to the use of energy-efficient technologies for saving both energy and money and one of them is the evaporative cooling technology use [27-29]. With the undergoing pollutant emission constraints and electricity disaster, the use of the evaporative cooling system is very beneficial. In the present work, detailed review of various kind methods of evaporative cooling systems and work related to that are reported. The important factor that 
suggests the use of evaporative coolers is the difference in the wet bulb and outside air dry-bulb temperature. With an evaporative cooling system, one can reduce the incoming ambient air temperature to the room to a great extent. Precooling of water could enhance a direct evaporative cooler that cools the air even below its inlet WBT.

The reduction in temperature comes at the expense of greater relative humidity. It may be disadvantaged in certain applications. Various attempts have been made to study the effect of number parameters on the evaporative cooler performance. The pad material, pad thickness, air velocity, water circulation rate, and flow arrangements are found to have an effect on the overall performance of such evaporative coolers. For the given conditions, there exists a superior pad thickness balancing the evaporation rate and pressure drop across the pads. Various other methods, like a thermal curtain, providing water filament guides over the external facet of the building, evaporative walls, are being attempted. Efforts have been made to model the performance of evaporative cooling systems and reasonable agreements between the predictions and experiments are reported.

\section{REFERENCES}

[1]. E. Hajidavalloo, Application of evaporative cooling on the condenser of window-air-conditioner, Applied Thermal Engineering 27 (2007) 1937-1943

[2]. Z. Duan et al., "Indirect evaporative cooling: Past, present and future potentials," Renewable and Sustainable Energy Reviews, vol. 16, pp. 6823-6850, 2012

[3]. O. Amer, R. Boukhanouf, and H. G. Ibrahim, A Review of Evaporative Cooling Technologies, International Journal of Environmental Science and Development, Vol. 6, No. 2, February 2015.

[4]. Zahra Giabaklou* John a. Ballinger ,A passive evaporative cooling system by Natural ventilation, Budding and Environment, vol. 31, no. 6, pp. 503-507, 1996

[5]. Ashutosh Mittal a, TarunKataria a, Gautam K. Das b \&Siddharth G. Chatterjee, Evaporative Cooling of Water in a Small Vessel Under Varying Ambient Humidity, International Journal of Green Energy, 09 October 2014, Publisher: Taylor \& Francis.

[6]. Nishikant Z. Adkane, Saroj V. Borkar , Ramesh D. Bokde, "Comparative analysis of domestic refrigerator by using water cooled condenser with air cooled condenser", International Research Journal of Engineering and Technology, Vol. 4, Issue 06, June -2017.

[7]. C. Kittas; T. Bartzanas1; A. Jaffrin, Temperature Gradients in a Partially Shaded Large Greenhouse equipped with Evaporative Cooling Pads Biosystems Engineering (2003) 85(1), 87-94 Publisher Elsevier Science Ltd

[8]. Jiang He- ${ }^{*}$, Akira Hoyano ,Experimental study of cooling effects of a passive evaporative cooling wall constructed of porous ceramics with high water soaking-up ability ,Building and Environment (2010) 461-472, publisher Science direct.

[9]. B.N. Taufiq*, H.H. Masjuki, T.M.I. Mahlia, M.A. Amalina, M.S. Faizul, R. Saidur, Exergy analysis of evaporative cooling for reducing energy use in a Malaysian building ,The Ninth Arab International Conference on Solar Energy (AICSE-9), Kingdom of Bahrain, publisher Science direct.

[10]. R. Navon* H. Arkin, Feasibility of Direct-Indirect Evaporative Cooling for Residences, Based on Studies with a Desert Cooler, Building and Environment, Vol. 29, No. 3, pp. 393-399, Elsevier Science.
[11]. Gómez, E.V., Martínez, F.J.R., Diez, F.V., Leyva, M.J.M., Martín, R.H., 2005. Description and experimental results of a semi-indirect ceramic evaporative cooler. Int. J. Refrig. 28, 654-662

[12]. Y.J. Dai, K. Sumathy, Theoretical study on a cross-flow direct evaporative cooler using honeycomb paper as packing material, Building and Environment 45 (2010) 461-472, Elsevier Science

[13]. Tilahun Seyoum Workneh*, G. Osthoff and M. S. Steyn ,Integrated agrotechnology with preharvestComCat ${ }^{\circledR}$ treatment, modified atmosphere packaging and forced ventilation evaporative cooling of tomatoes, African Journal of Biotechnology Vol. 8 (5), pp. 860872, 6 March, 2009.

[14]. Chainarong Chaktranond, Doungsong Peachrakha, An Experimental Evaluation of Energy Saving in a Split-type Air Conditioner with Evaporative Cooling Systems ,International Transaction Journal of Engineering, Management and Applied Science and Technologies, 2010.

[15]. Hisham El-Dessouky*, Hisham Ettouney, Ajeel Al-Zeefari ,Performance analysis of two-stage evaporative coolers ,Chemical Engineering Journal 102 (2004) 255-266.

[16]. E. Kimmel; H. Arkin; D. Broday, A. Berman, A Model of Evaporative Cooling in a Wetted Hide, j. Ugric. Engng res. (1991) 49, 227-241

[17]. Wojciech Zalewski a, Piotr Antoni Gryglaszewski b ,Mathematical model of heat and mass transfer processes in evaporative fluid coolers, Chemical Engineering and Processing 36 (1997) 271-280.

[18]. M. Sweetland and J. H. Lienhard V, Evaporative Cooling of Continuously Drawn Fibers by Water Sprays, Int. J. Heat Mass Transfer, vol. 43, p. 777, 2000.

[19]. Yash R., Satyawan D. , Performance Improvement Techniques for Evaporative Air Cooler - A Review ,International Journal of Engineering Research \& Technology (IJERT), ISSN: 2278-0181,Vol. 6 Issue 03, March-2017.

[20]. Y.A. Cengel, M.A. Boles, Thermodynamics An Engineering Approach, third ed., McGraw-Hill, Boston, 1998.

[21]. R.J. Dossat, Principal of Refrigeration, Prentice Hall, NewJersey, 1991.

[22]. W.K. Brown, Fundamental concepts integrating evaporative techniques in HVAC systems, ASHRAE Transactions 96 (Part 1) (1990) 1227-1235.

[23]. D.Y. Goswami, G.D. Mathur, S.M. Kulkarni, Experimental investi- gation of performance of a residential air conditioning system with an evaporatively cooled condenser, Journal of Solar Energy Engineering 115 (1993) 206-211.

[24]. E .Hajidavalloo, Increasing COP of window air conditioner in very hot weather of Khoozestan, Research Project Report to Management and Programming Organization,2001.

[25]. G.J. Van Wylen, R.E. Sonntag, Fundamental of Classical Thermodynamics, third ed., John Wiley and Sons, New York, 1986.

[26]. Cuce PM, Riffat S. A comprehensive review of heat recovery systems for building applications. Renew Sustain Energy Rev2015;47:665-82.

[27]. Li X, Bowers CP, Schnier T. Classification of energy consumption in buildings with outlier detection. IEEE TransInd Electron 2010;57(11):3639-44

[28]. Cuce E, Cuce PM, Wood CJ, Riffat SB. Toward aerogel based thermal superinsulation in buildings: A comprehensive review. Renew Sustain Energy Rev 2014;34:273-99.

[29]. Zhao H, Magoules F. A review on the prediction of building energy consumption. Renew Sustain Energy Rev 2012;16:3586-92. [48] Sadineni SB, Madala S, Boehm RF. Passive building energy savings: a review of building envelope components. Renew Sustain Energy Rev 2011;15:3617-31. 